http://jmscr.igmpublication.org/home/

ISSN (e)-2347-176x ISSN (p) 2455-0450

crossref DOI: https://dx.doi.org/10.18535/jmscr/v9i11.15

Journal Of Medical Science And Clinical Research

IGM Publication

An Official Publication of IGM Publication

\title{
Anaesthetic Management of a Case of Cleft Lip Planned For Cleft Lip Repair - A Case Report
}

\author{
Authors \\ Dr Sujithra.K ${ }^{1}$, Dr Vijaykumar ${ }^{2}$, Dr Sandeep $\mathbf{U}^{3}$, Dr Monica ${ }^{4}$ \\ ${ }^{1}$ Postgraduate Student, Department of Anaesthesiology, CHRI \\ ${ }^{2}$ Department of Anaesthesiology CHRI \\ ${ }^{3}$ Department of Plastic Sugery, CHRI \\ ${ }^{4}$ Postgraduate Student, Department of Anaesthesiology, CHRI, Kelambakkam-Chennai
}

\begin{abstract}
Cleft lip with or without palate is one of the most common congentialmal formations, has a huge impact on the life of an individual and their family. Bearing in mind the challenges involved in the anaesthesia for cleft lip surgery includes difficult airway, inadvertent extubation, aspiration of blood and secretions, laryngospasm. Children with clefts should be managed by a multidisciplinary team of experts, which is discussed here.

Keywords: cleft lip, paediatric age, difficult airway.
\end{abstract}

\section{Introduction}

Cleft lip with or without palate is one of the most common congenital malformations, Incidence in worldwide is 1 in 700 live birth and it is nearly 1 in 500 in India $^{(1)}$. It has a great negative social impact on the patient and his/her family. Cleft lip and palate results in complications such as affecting feeding, speech, hearing and psychological development. Etiology of cleft lip and palate is aninteraction between genetic and environmental factors. Defects in palatal growth during the first trimester result in cleft lip. Teratogenic exposure associated with cleft lip includes maternal consumption of alcohol, smoking, anticonvulsants, salicylates and cortisone $^{(3)}$. Child with cleft lip may have associated abnormalities, ranging from 4.3 to $64 \%{ }^{(2)}$. Craniofacial abnormalities are most common, followed by congenital cardiac disease, renal and abdominal defect, CNS abnormalities.

All patients require anaesthesia for primary repair and presents with a significant challenge where the airway is shared with the surgeon involved, and also may encounter difficult laryngoscopy and intubation. Preoperative visits should allow time to assess general and specific problems like anaemia, respiratory tract infections, associated congenital anomalies, poor weight gain. Airwayrelated problems in cleft patients, account for majority of anaesthetic morbidity and mortality ${ }^{(1)}$.

\section{Case Report}

A 11-month-old female child in Fig.1 weighing $8.5 \mathrm{~kg}$, normal milestones attained for age, immunized till date, who had congenital cleft lip was admitted in hospital for the cleft lip repair. The child evaluated by a multidisciplinary team 
involving anaesthesiologist, surgeon, paediatrician, cardiologist and counselled regarding the perioperative care. Informed and written consent form was obtained from the parents. Routine blood investigations (complete blood picture - haemoglobin - 10gms, total count15500 cells $/ \mathrm{mm} 3$, platelet count -1.34 lakhs, random blood sugar, serum creatinine, blood grouping - $\mathrm{O}$ positive, clotting time, bleeding time, human immunodeficiency virus I and II, and hepatitis B surface antigen, ECHO, chest X-ray were done. Mallampati could not be assessed, neck movements were normal. Pre-operative fasting advised as per American society of Anaesthesiologits fasting guidelines. Baseline vital parameters such as heart rate, non-invasive blood pressure, electrocardiogram, temperature, and peripheral capillary oxygen saturation $(\mathrm{SpO} 2)$ were monitored inside the operation theatre.Heart rate was 122 beats/minute, Respiratory rate was $24 /$ minute, $\mathrm{SpO} 2$ was $100 \%$ in room air. Intravenous line was secured with 24 gauge cannula in right dorsum of hand.

Prophylactic antibiotic and Premedication, Inj Atropine $0.08 \mathrm{mg}$, inj midazolam $0.5 \mathrm{mg}$, and inj.fentanyl $20 \mathrm{mcg}$ was given intravenously and preoxygenated with $100 \%$ oxygen for 3 minutes with anatomical face mask and induced with sevoflurane 2-4 \% and injpropofol20mg intravenously. Bag and mask ventilation was possible and hence injatracurium $4 \mathrm{mg}$ was given intravenously.Intially intubation tried with Macintosh blade, larynx was not visualized and CL grading was IV,after failed attempt Miller blade NO.1 used, Trachea was intubated with endotracheal tube of size 3 uncuffed south pole Ring-Adair-Elwyn (RAE) tube by giving backward, upward, rightward pressure (BURP). Bilateral air entry was checked and found to be equal. Throat packing was done, EtCO2 confirmed the correct placement and the tube was fixed. Anesthesia was maintained with sevoflurane $1-2 \%$ in $\mathrm{O} 2$ and $\mathrm{N} 2 \mathrm{O}$, Inj. atracurium $0.25 \mathrm{mg}$ topup was given. Bair hugger warmer was applied for the baby to prevent hypothermia.
Intraoperative vital signs remained stable. Blood loss was around $25 \mathrm{ml}$ and total IV fluids given were according to Holliday segar formula. Paracetamol suppository (250 mg) was given for postoperative analgesia. At the end of the surgery after attained spontaneous respiration, muscle relaxation was reversed with inj neostigmine $0.4 \mathrm{mg}$ and inj atropine $0.08 \mathrm{mg}$. Throat pack was removed and the child was extubated uneventfully. Postextubation vital signs were normal and shifted to PICU.

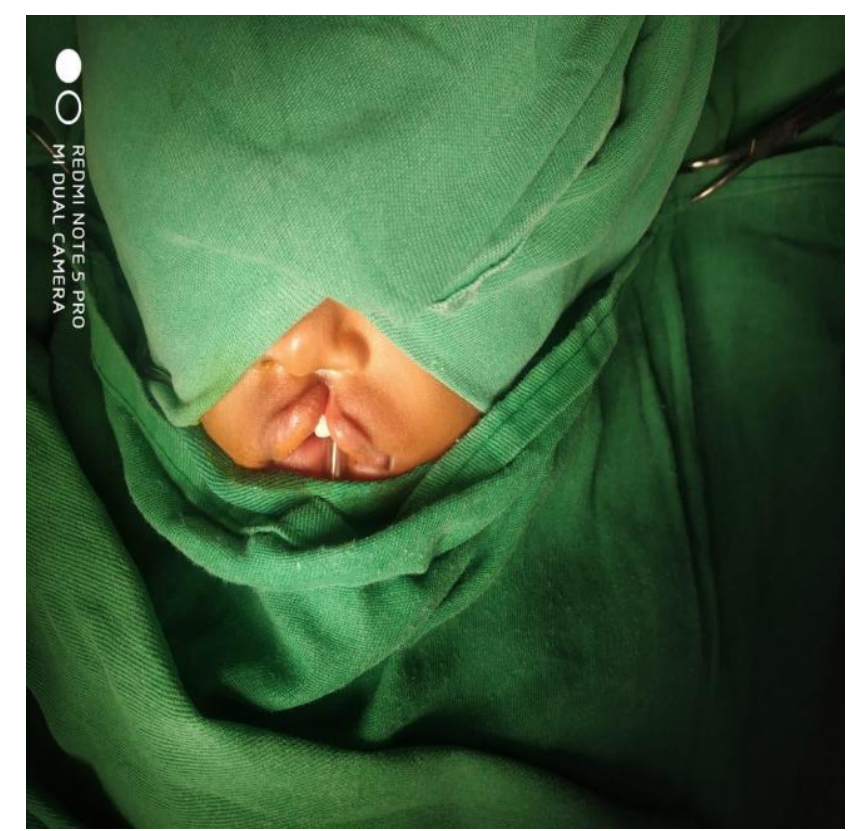

Figure 1: Intraoperative image showing cleft lip with RAE tube

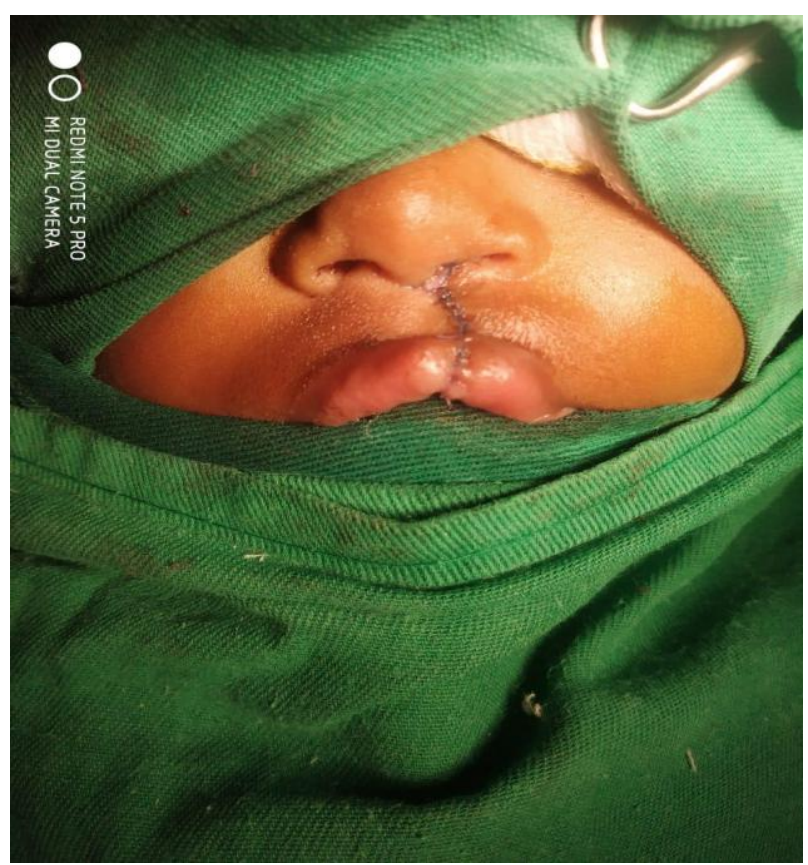

Figure 2: Postoperative image after surgery 


\section{Discussion}

Fogh- Anderson First defined genetic involvement of cleft lip and palate ${ }^{(9)}$. The prevalence of clef ting ranges from 1:300-1200 live births for cleft $\operatorname{lip}^{(3)}$. Cleft deformities are more common in people of Asian descent $(1: 500)^{(3)}$. Cleft lip and cleft lip/palate is more prevalent in males whereas cleft palate is more prevalent in females. Most clefts are caused by the interaction between genetic and environmental factors. Increased maternal age, maternal alcohol, phenytoin during pregnancy are considered to be main causes. Clefting occurs when there is failure of fusion, or diminished mesenchymal penetration between these migrating embryological processes. Cleft lip is the consequence of failed fusion between the medial nasal and maxillary processes on one or both sides. The cleft may affect only the upper lip, or it may extend more deeply into the maxilla and the primary palate (orofacial cleft). A variety of complete, incomplete, unilateral and bilateral clefts can occur. If the fusion of palatal shelves is also impaired, the cleft lip is accompanied by cleft palate. This usually occurs at the junction between the central and lateral parts of the upper lip on either side. Cleft lip is unilateral in $75-80 \%$ of cases, with the left side more commonly affected; $20-25 \%$ are bilateral. $^{(11)}$ A spectrum of abnormality ranging from a notch in the upper lip lateral to the midline, to a bilateral cleft extending up into the nose and alveolar ridge (gums) or hard palate may be seen. Midline clefts are rare and are usually a feature of an underlying syndrome. Approximately 150 syndromes have a cleft as a feature. The more common of these syndromes include the Pierre Robin sequence; TreacherCollins syndrome; Goldenhar syndrome; 22q deletion (velocardiofacial syndrome); van der Woude syndrome; Fetal alcohol syndrome, Stickler syndrome; and Opitz syndrome. Cardiac defects, renal anomalies are also relatively common, but may be missed. The incidence of clefts and cardiac defects ranges from 1.3-51\%. ${ }^{(11)}$ In 1847 John Snow reported the use of open drop ether and chloroform on 3-6 week old infants undergoing cleft lip repair, unprotected airway and airway obstruction restricted surgeons to perform surgery. It was only later in the 1930's, endotracheal tubes were introduced. The airway, cardiac defects, renal pathology or other malformations need to be addressed. Many infants fail to thrive. Historically, surgery was planned according to "Kilners rule of 10 ": at 10 weeks of age, a weight of $10 \mathrm{lb}$ and haemoglobin $10 \mathrm{gm} / \mathrm{dl}$ for cleft $\operatorname{lip}^{(1)}$.A history of feeding difficulties coupled with a failure to thrive suggests a severe defect. Given the abnormalities of the face, concern may exist regarding the difficulty of mask ventilation and endotracheal intubation. Unlike the adult population there are not any objective criteria that can help to identify a difficult airway. Pre-operative history should also focus on determining if the baby has an URI- patients with URI are at increased risk of bronchospasm, laryngospasm, desaturations, postintubation croup. Perinatal background such as pregnancy evolution, kind of delivery,complications during delivery, non pathologic background related with nutritional state and developments houls be addressed. Physiological anaemia is likely when surgery is performed at around 3 months of age. Failure to thrive and repeated infections may contribute to the severity of the anaemia ${ }^{(9)}$. Although blood loss is usually insignificant, hemoglobin level should be kept in mind and packed cells should be kept ready. Preoperative sedation is avoided in view of difficult intubtion. Anti-cholinergic is used (atropine, glycopyrrolate) to reduce secretions, or to maintain the ratedependant cardiac output in small infants. In order to overcome one of the difficulties associated with the intubation of infants with left-sided defects, some authors have suggested placing a roll of gauze or a dental swab in the defect, to prevent the laryngoscope becoming caught in a deep cleft ${ }^{(6)}$. In bilateral cleft lip, the vomer or central lip prominence can hinder midline laryngoscopy. A straight laryngoscope blade and a lateral approach may overcome this problem. Most would use an inhalation induction with sevoflurane to ensure 
that intubation is possible before using muscle relaxants. South-facing RAE tubes are most useful for endotracheal intubation ${ }^{(8)}$. If a Boyle-Davis gag is used for the palate repair, ensure that the RAE tube does not become snared within the blades of the gag, and when the gag is opened, ensure that the endotracheal tube is not kinked or pushed down into a bronchus. ${ }^{(7)} \mathrm{A}$ throat pack should always be used to prevent soiling of the airway or ingestion of blood. It mustbe removed prior to extubation. Anesthesia is maintained with sevoflurane with or without opioids. Careful suctioning of the mouth and pharynx and a check for oozing from the surgical site prior to extubation is prudent. Micrognathia or other congenital anomalies involving the upper airway can cause respiratory problems in the immediate postoperative period. Extubation should therefore be delayed until the child is fully awake. Extubation in the left lateral position when the child is fully awake is considered safest. Pressure from the Boyles Davis gag may cause swelling, oedema or ischaemia of the tongue in prolonged surgery and cause airway obstruction. The nasal airway usually remains patent after cleft lip repair.Hypothermia is directly proportional to length of surgery and temperature of surgical room, it is critical to keep the surgical room at an adequate temperature to avoid adverse events. An infra-orbital nerve block has proved useful in neonates, infants for postoperative analgesia along with NSAIDS ${ }^{(5)}$.

\section{Conclusion}

Anaesthesia for cleft lip and cleft palate surgery may range from extremely challenging with difficult airway and congenital heart disease, to fairly simple defect of the upper lip. A high index of suspicion for conditions associated with cleft lip should be in mind. Routine preoperative assessment with difficult airway cart preparation is must. A difficult laryngoscopy is a more frequent than difficult intubation. Patients should be extubated when fully awake with close observation for signs of airway obstruction. Analgesia is important for the balanced anaesthetic technique. Children with clefts could be managed efficiently by a multidisciplinary team of experts.

\section{Bibliography}

1. Bosenberg AT. Anesthesia for cleft lip and palate surgery. SAJAA 2007; 13(5):9-14.

2. Sandberg DJ Magee WP Denk MJ Neonatal cleft lip and cleft plate repair AORN 2002;75: 490-99.

3. Clinical approach In: Firth $\mathrm{H}$ Hurst $\mathbf{J}$ eds Clinical Genetics Oxford Medical Press Oxford 2006. Chap 2:74-77.

4. Van Boven MJ Pendeville PE Veyckemans F Janvier C Vandewalle F Bayet B Vanwijck R. Neonatal cleft lip repair: the anaesthesiologists point of view Cleft Palate Craniofacial J 1993; 30: 574-8.

5. Bosenberg AT, Kimble FW: lnfraorbital nerve block in neonates forcleft lip repair Anatomical study and clinical application. $\mathrm{Br}$ J Anaesth 1995; 74:506-508.

6. Gunawardana RH Difficult laryngoscopy in cleft lip and palate surgery. Brit J Anaesth 1996; 76:757-59.

7. Xue FS Zhang GH Li P Sun HT Li CW Liu KP Tong SY Liao X ZhangYM. The clinical observation of difficult laryngoscopy and difficult intubation in infants with cleft lip and palate PaediatrAnaesth.2006;16:283-89.

8. Bolton P. Anaesthesia for cleft lip and palate surgery. AnaesIntens Care Med 2006; 7:157.

9. Doyle E, Hudson I: Anaesthesia for primary repair of cleft lip andpalate: A review of 244 procedures. Paediatr Anaesth 1992; 2:139145.

10. Fogh-Anderson P. Inheritance of herelip and cleft palate. Copenhagen: Munksgaard; 1942.

11. Hatch D. Airway management in cleft lip and palate. Brit J Anaesth1996; 76:755-56. 